LIAMES, Campinas, SP, v. 19, 1-23, e019014, 2019

\title{
A ortografia da língua Awetí
}

\author{
Sebastian Drude \\ Museu P.E. Goeldi, Brasil/Goethe-Univers. Frankfurt \\ https://orcid.org/0000-0002-2970-7996
}

\section{Waranaku Awete e Awajatu Aweti Professores indígenas do povo Aweti, Brasil}

\begin{abstract}
This article describes and substantiates the orthography of the Awetí language (Tupí, Alto Xingu/ мT), based on the analysis of the phonological and grammatical structure of Awetí. The orthography is a result of a long collaborative effort of the three authors, started in 1998. It establishes more than an alphabet (the representation of the vowels and consonants of the language): it also deals with internal variation, resyllabification, lenition, and other (morpho)phonological processes. Special attention was given to the written representation of the glottal stop, as well as the orthographical consequences of nasal harmony. Although the lexical accent (stress) is not explicitly marked in Awetí, most of its affixes and particles are examined as to their stress and interaction with neighboring morphemes, also determining orthographical words. Finally, the alphabetical sort order is established, where digraphs are treated as regular sequences of letters, and the glottal stop $\langle '\rangle$ is ignored, which helps learners of Awetí. The orthography as described here has now been used for some 10 years in the village school for alphabetizing in Awetí, with good results. We believe that several of the arguments raised here can be fruitfully transferred to other languages with similar phenomena (glottal stop as consonant, nasal harmony, morpho-phonological assimilation, etc.).
\end{abstract}

KEYWORDS: Awetí; Orthography; Writing; Alphabet; Phonology.

RESUmo: Este trabalho descreve e fundamenta a ortografia da língua Awetí (Tupí, Alto Xingu/MT), com base na análise da estrutura fonológica e gramatical do Awetí. A ortografia é resultado de um longo trabalho colaborativo entre os três autores, iniciado em 1998. Ela não define apenas um alfabeto (a representação das vogais e das consoantes da língua), mas também aborda a variação interna, ressilabificação, lenição, palatalização e outros processos (morfo)fonológicos. Tanto a representação escrita da oclusiva glotal, quanto as consequências ortográficas da harmonia nasal receberam uma atenção especial. Apesar de o acento lexical não ser ortograficamente marcado em Awetí, a grande maioria dos afixos e partículas é abordada considerando o acento e sua interação com morfemas adjacentes, ao mesmo tempo determinando as palavras ortográficas. Finalmente foi estabelecida a ordem alfabética em que dígrafos são tratados como sequências de letras, já a oclusiva glotal 〈'〉 é ignorada, facilitando o aprendizado do Awetí. A ortografia tal como descrita aqui tem sido usada por aproximadamente dez anos na escola para a alfabetização em Awetí, com bons resultados obtidos. Acreditamos que vários dos argumentos aqui levantados podem ser produtivamente transferidos para outras línguas com fenômenos semelhantes (a oclusiva glotal como consoante, harmonia nasal, assimilação morfofonológica, etc.).

PalaVras ChaVes: Awetí; Ortografia; Escrita; Alfabeto; Fonologia. 


\section{DRUDE, W. AWETE e A. AWETI - A ORTOgrafiA DA LÍNgUA AwEtí}

\section{Introdução}

Este artigo descreve pela primeira vez as regras e convenções da representação escrita da língua Awetí (Tronco Tupí, falada no Parque do Xingu, Mato Grosso). Tratase do resultado de uma pesquisa colaborativa do autor principal, Sebastian Drude, com especialmente os dois professores Awetí, coautores deste trabalho, Waranaku Awete e Awajatu Awetí, e é baseado em vários anos de estudo linguístico realizado por Drude.

Em 1998, quando Sebastian Drude visitou a aldeia pela primeira vez, os Awetí já tinham dado os primeiros passos na escrita da sua língua, usando uma proposta inicial de Ruth Monserrat, que estudara a língua no final dos anos 1960 e início dos anos 1970 (cf. Emmerich \& Monserrat 1972; Monserrat 1976). Nos anos 90, o Instituto Socioambiental (ISA) começou um projeto de formação de professores do Parque Indígena do Xingu. Neste contexto, solicitou a colaboração de Ruth Monserrat, que contribuiu com uma tabela em que cada som identificado é relacionado a uma letra ou a um dígrafo (Monserrat 1992). Esta proposta de alfabeto (mais exatamente, das relações fonema-grafema) continua, em geral, válida até hoje. Porém, uma ortografia tem, além desta relação, muitas outras questões a serem solucionadas, como queremos demonstrar neste trabalho. Estamos apresentando as regras às quais chegamos depois de 10 anos trabalhando juntos. Diferentemente de muitos outros casos, como os discutidos por D'Angelis (1994), Meira (2004) e Franchetto (2008), temos aqui um caso feliz em que a introdução da escrita vem sendo acompanhada desde o início pela assessoria de linguistas treinados que se dedicaram e se dedicam ao estudo da língua, e em que não há ortografias inadequadas, previamente estabelecidas e/ ou concorrentes.

Os Awetí solicitaram o apoio de Drude, em 1998, principalmente porque precisavam de consultoria para introduzir a escrita da língua. Como eles mesmos explicaram, a tabela do alfabeto Awetí não era suficiente para escrever com segurança. Ao contrário, muitas dúvidas surgiam ao se redigir frases e textos inteiros. Esclarecer e solucionar estas dúvidas foi um longo processo colaborativo. Logo nos primeiros anos identificamos várias partículas (clíticos) que antes eram muitas vezes escritas junto com a palavra anterior (isto aparentemente é bastante comum; em várias línguas o que à primeira vista parecem ser sufixos revelam-se depois serem partículas). Também discutimos bastante, em 1998 e 1999, sobre como escrever as consoantes no final de morfema que podem sofrer lenição e que correspondem em sua nasalidade e oralidade com as vogais anteriores.

Assim, aos poucos estabelecemos juntos as regras descritas abaixo, primeiro somente nós três, depois incluindo as opiniões e os questionamentos feitos por parte dos primeiros alunos que foram sendo alfabetizados em Awetí. ${ }^{1}$ A partir de 1999, a escrita e a alfabetização na língua, em princípio, já se baseavam na maioria das regras aqui descritas. Estas foram refinadas e completadas nos anos 2001-2005 durante um projeto de documentação da língua. Existe, hoje, um corpus de quase 40 horas de textos transcritos na ortografia (Drude; Reiter; Lieb 2006). Na criação deste material, participaram no final

${ }^{1}$ Há uma cartilha (Troncarelli et.al. 2002), na produção da qual o ISA contou com a colaboração dos três autores deste artigo. Porém, a edição da cartilha foi finalizada antes que a ortografia se consolidasse suficientemente e, por isso, a cartilha contém inconsistências (internas e com as regras descritas neste artigo) e acabou não sendo muito utilizada na escola Awetí. 
do projeto seis Awetí, especialmente os dois coautores deste trabalho, assim como Tawyjat e Parawajru Awetí. Este projeto colaborativo proporcionou inúmeras oportunidades para discutir dúvidas sobre como escrever mais apropriadamente em Awetí, e assim, para refinar as regras da ortografia.

Neste processo, o autor principal sempre procurou exercer o papel de um assessor que explica o que entendeu sobre o sistema da língua, coletando e expondo as possíveis representações na ortografia, e dando a sua opinião sem a impor aos falantes nativos. $\mathrm{O}$ objetivo foi que estes fizessem suas escolhas, mas não de maneira aleatória ou inconsistente, mas sim bem informados e cientes das opções e suas consequências. Nem sempre a solução inicialmente sugerida pelo linguista foi adotada e, quando isto aconteceu, usualmente a discussão sobre este ponto da fonologia e ortografia foi muito frutífera para nós três, pois aprendemos mais detalhes sobre a estrutura da língua. ${ }^{2}$ Concordamos que, quanto mais a ortografia estiver baseada no conhecimento da estrutura da língua, será mais apropriada e mais fácil de entender e ensinar.

Elaboramos o presente artigo juntos em 2007 durante uma estadia de duas semanas dos dois coautores na casa do autor principal. Para isto, recapitulamos primeiro os fatos e as regras. Em seguida, Sebastian Drude formulou uma proposta para o texto deste artigo, que foi lida (explicando a terminologia especializada) e discutida (frase por frase), muitas vezes alterada em consequência destas discussões, e finalmente aprovada por nós três. ${ }^{3}$

Há várias questões que, pelos fatos subjacentes à língua, permitiriam, aparentemente, diferentes soluções. Tentamos aqui, nestes casos, justificar e ilustrar aquela que adotamos por considerá-la a mais apropriada. ${ }^{4}$ Sabíamos, em 2007, que estudos mais profundos da fonética e da fonologia da língua, assim como a aplicação das regras, em sala de aula, a futuros alunos com outros conhecimentos poderão trazer, eventualmente, novos argumentos a serem considerados e que poderão, em um ou outro caso, mostrar que há outras soluções melhores. Hoje, mais do que dez anos depois, podemos relatar que a ortografia se consolidou na prática, em particular na escola e na alfabetização em Awetí. ${ }^{5}$

Além do princípio de representar na escrita, sempre que possível e factível, um fonema pela mesma letra (ou por um dígrafo ${ }^{6}$ ), há um outro princípio que procuramos

${ }^{2} \mathrm{O}$ presente artigo não pretende fundamentar ou argumentar pela análise fonológica, cujo resultado é pressuposto aqui, e que será apresentada com detalhes em outra ocasião (Drude, em preparação). No entanto, os fatos mais importantes foram apresentados em Drude (2009, sobre a harmonia nasal), e Drude (2011, sobre a prosódia, com um esboço do sistema fonológico, incluindo a estrutura silábica).

${ }^{3}$ Agradecemos a todos que participaram das discussões sobre a ortografia ao longo dos anos, especialmente a Tawyjat Awetí e a Sabine Reiter. Também agradecemos esta última e Bruna Franchetto e Ana Carolina Ferreira Alves pelas sugestões para melhorar este documento, bem como os revisores anônimos e last but not least Rui Neves e Ivan Rocha, que ajudaram na redação da revisão final. (Em 2009, texto deste artigo já tinha sido revisado e aceito para a publicação na revista 'Estudos e Pesquisas' da FUNAI, que, porém, foi descontinuada antes da sua publicação.)

${ }^{4}$ Ainda assim, usualmente não há espaço aqui para retraçar todas as opções consideradas e todos os raciocínios que justificam as regras escolhidas.

${ }^{5}$ Apesar do nome do seu artigo, Figueiredo (2009) não trata da prática da escrita ou da ortografia, nem menciona o projeto de documentação e suas consequências entre os Awetí.

${ }^{6}$ Falamos de um digrafo (ou 'multígrafo') quando duas (ou mais) letras são combinadas para representar um fonema, como no caso do $\langle\mathbf{c h}\rangle$ em português, que representa o som $/ \mathbf{J} /$ - função que em tem o dígrafo $\langle\mathbf{s h}\rangle$ em inglês (ou o multígrafo $\langle\mathbf{s c h}\rangle$ em alemão). 
seguir. Este é o 'princípio morfemático', que visa à constância da grafia de raízes e afixos (dos morfemas). Isto quer dizer que, se há, num certo contexto, mais do que uma opção de escrever um morfema, é preferível escrevê-lo da mesma forma como em outros contextos, o que vai facilitar o reconhecimento dos morfemas e a absorção direta do conteúdo na

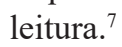

Procuramos evitar um elevado nível técnico neste texto, para facilitar a recepção e aplicação da ortografia por não-linguistas. De fato, a discussão deve ser de interesse mesmo para não-linguistas e para pessoas que não pretendem aprender o Awetí, servindo como um exemplo e ilustrando o espectro dos tópicos a serem considerados.

\section{A representação das vogais}

\subsection{Representação básica}

A língua Awetí tem seis vogais básicas $/ \mathbf{i}, \mathbf{i}, \mathbf{u}, \boldsymbol{\varepsilon}, \mathbf{a}, \mathbf{\jmath} /,{ }^{8}$ que são representadas, cada uma, por uma letra do alfabeto latino: $\langle\mathbf{i}, \mathbf{y}, \mathbf{u}, \mathbf{e}, \mathbf{a}, \mathbf{o}\rangle$, respectivamente. Aparentemente, somente a representação escrita $\langle\mathbf{y}\rangle$ para $/ \mathbf{i} /$ precisa de uma justificativa, pois este som não existe na maioria das línguas que se utilizam do alfabeto latino. Optamos pelo $\langle\mathbf{y}\rangle$, apesar de que esta letra represente em Inglês, e, consequentemente, em grande parte da tradição americanista, o glide [j]. Esta decisão se apoia nos seguintes fatos:

- na sua origem (e também no alfabeto fonético internacional, IPA) a letra $\langle\mathbf{y}\rangle$ representa uma vogal alta, semelhante ao /i/ (cf. seu nome em Espanhol, 'i griega');

- a alternativa mais considerada, em uso por exemplo em Karib do Alto Xingú, seria o $\langle\ddot{i}\rangle$, mas este criaria o problema de combinar o trema com o til;

- seguindo a tradição Tupinista (onde a representação de /i// por $\langle\mathbf{y}\rangle$ é frequente; ver a discussão breve de A. Rodrigues (1986: 10ss)), Ruth Monserrat já sugeriu esta representação, e ela já se consolidara.

\subsection{Variação entre /o/ e /u/, e entre /o/ e/a/}

Em geral, os fonemas /u/ e /o/ são inequivocamente distintos em Awetí, como mostram pares mínimos como /a'to/ 'eu vou/fui' vs. /a'tu/ 'avô' (vocativo); /'sp/ 'folha'

${ }^{7}$ Este princípio morfemático foi identificado (p.ex. sob o nome de 'Morphemkonstanz') no estudo da escrita do Alemão pelo menos desde o início dos anos 1980, cf. p.ex. Eisenberg 1983, Fuhrhop 2005. Por exemplo, as duas formas da palavra Alemã para 'roda' [ва:t] (singular) е [ве:de] (plural, também [вє:de] оu ainda [вæ:dø], dependendo da região) não são escritos $\langle$ rat $\rangle$ e $\langle$ reder $\rangle$ (representações resultantes do padrão de escrever cada um dos sons envolvidos), mas sim, $\langle$ rad $\rangle$ e $\langle$ räder $\rangle$. Assim, o morfema lexical é reconhecível em ambas as formas: nas duas formas, usa-se um $\langle\mathbf{a}\rangle$ (uma vez com trema, com pronúncia diferente), e em ambas, usa-se um $\langle\mathbf{d}\rangle$ (uma vez com pronúncia de [t] , de acordo com a dessonorização final do Alemão). De fato, este princípio morfemático pode ser encontrado, embora em grau variado, em quase todas as línguas que usam ortografias alfabéticas.

${ }^{8}$ Utilizamos neste trabalho, na representação fonética e fonológica, os símbolos do Alfabeto da Associação Internacional de Fonética (IPA) e, como de costume, indicamos unidades fonéticas por colchetes “[...]", unidades fonológicas por barras " \%.../" e unidades ortográficas por ângulos "〈....", ou em negrito e itálico. 
vs. /'up/ 'pai', ou /o' pap/ 'acabou' vs. /u' pap/ 'lugar (para se guardar algo)'. Porém, há várias palavras em que há variação entre / / / e/u/ entre diferentes falantes ou mesmo em

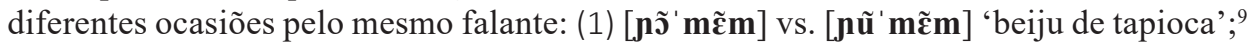

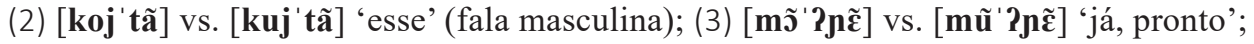
(4) [mo' 'at $]$ ] vs. [mu' 'at $]$ ' 'pessoa (civilizada)' etc. Não queremos estabelecer uma norma que privilegie um grupo de falantes Awetí frente a outros, e por isso, neste caso, achamos apropriado permitir as duas grafias das respectivas palavras, refletindo as preferências (em um dado momento ou contexto) de cada escritor. Portanto, no caso dos exemplos acima são corretos e aceitáveis tanto 〈jomem〉 quanto 〈jumem〉 ('beiju'), $\langle\mathbf{m u}$ 'jẽ $\rangle$ e também $\langle\mathbf{m o}$ 'jẽ $\rangle$ ('já'), e assim por diante, a critério de cada escritor.

O mesmo vale para o pronome de primeira pessoa 'exclusiva' (nós sem você) e o prefixo relacionado, onde encontramos uma variação entre / $\mathbf{~ / ~ e ~ / a / : ~ s a ̃ o ~ c o r r e t a s ~ a m b a s ~ a s ~}$ formas, (5) $\langle\mathbf{o z o z a}\rangle$ e $\langle\mathbf{a z o z a}\rangle$ (pronome), (6) $\langle\mathbf{o z o}\rangle$ e $\langle\mathbf{a z o}\rangle$ (prefixo). (Inclusive, há indícios que pelo menos para alguns falantes há uma diferença na funcionalidade / semântica destas duas formas do prefixo em certos contextos verbais). ${ }^{10}$

\subsection{Ressilabificação}

Em diferentes ocasiões há processos de ressilabificação de /u/ ou /o/ para [w], e de /i/ e

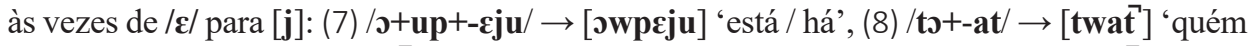
vai', (9) /o-+atuk/ $\rightarrow$ [watuk] 'ele toma banho', (10)/tãn+oks+-at/ $\rightarrow$ [tãnokwat ] 'quem sempre corre', (11) /i-+atuk/ $\rightarrow$ [jatuk] ' 'pode tomar banho!'.

A regra estabelecida por nós determina que, na maioria dos casos, é recomendado representar na escrita o resultado da ressilabificação e não as formas subjacentes, ou seja,

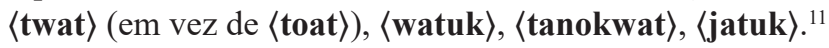

No entanto, no caso de [owpeju] e similares, o princípio morfemático foi observado, o que determina que as raízes subjacentes devam sofrer o menor número possível de alterações na grafia, escrevendo, portanto, $\langle\mathbf{o u p e j u}\rangle$, mantendo constante a grafia $\langle\mathbf{u p}\rangle$ para a raiz, e não $\langle\mathbf{o w p e j u}\rangle$. De fato, no caso de $\langle$ twat $\rangle$ a vogal ressilabificada $/ \mathbf{~} / \rightarrow$ [w] também pertence à raiz 〈to〉, então o critério não é de ser ou não parte da raiz ou do afixo, mas a diferenciação é entre uma vogal inicial da sílaba (que é alterada na escrita) e uma vogal final (que não pode ser alterada). Ou seja, há uma tendência de representar a ressilabificação somente quando a vogal se torna uma semivogal num ditongo crescente, mas não quando a semivogal resultante entra em posição final (ditongo decrescente). O mesmo vale para os sufixos onde pode acontecer ressilabificação, como no caso de 〈tanokwat〉 acima, ou no caso do sufixo do futuro nominal, (z)an'jap, que é uma forma (gramaticalizada) construída a partir do sufixo /(z)ãn/ 'na função de', com a raiz /RE/ 'dizer' e o sufixo /-ap/ '(nominalização de instrumento)': (12) /(z)ãn+1E+-ap/ $\rightarrow$

${ }^{9}$ Enumeramos os exemplos dados no texto em parênteses com uma fonte menor.

${ }^{10} \boldsymbol{a z o}$ - pode ter sua origem na combinação do prefixo verbal da primeira pessoa singular (verbos ativos) $\boldsymbol{a}$ - com o marcador para o comitativo, zo-, dando um sentido de 'eu (a-) [fiz x] junto com outros (zo-)', que é semelhante ao significado da primeira pessoa exclusiva ozo 'eu e outros (sem ser você) [fizemos x]'.

${ }^{11}$ Esta é uma das poucas ocasiões onde não seguimos o princípio morfemático (ver acima, nota 7), e também um dos vários casos onde a sugestão original feita pelo linguista S. Drude não prevaleceu. 
[(z)ãn?jap'] '(futuro nominal)', literalmente: 'o que serve para dizer que está na função de...', como em (13) ite'inizan'jap 'minha futura rede' (p.ex. para a matéria prima em processamento, cf. ite'iñ ' minha rede').

O entendimento das regras e da variação que regem esta ressilabificação ainda não está detalhado o suficiente para garantir que estas regras para a escrita sejam de fato as melhores. Por exemplo, parece haver variação entre diferentes falantes; formas como [towat] ou [ijatuk] parecem possíveis para alguns falantes. Para eles, é permitido escrever, por exemplo, 〈towat〉 ou 〈ijatuk〉. Obviamente, uma compreensão mais aprofundada do funcionamento da ressilabificação e, em geral, da fonética e fonologia das semivogais ou glides, pode resultar em uma nova reformulação mais detalhada da ortografia, caso se faça necessário.

\section{A representação das consoantes}

\subsection{Representação básica}

O Awetí apresenta quinze consoantes: /p, t, k, ?, m, n, $\mathbf{y}, \mathbf{t s}, \mathbf{z}_{\vartheta}(\mathbf{\gamma}),(\mathbf{h}), \mathbf{w}, \mathbf{j}, \mathbf{f}, \mathbf{l} /{ }^{12}$ Embora o status fonológico de / / / e /h/ no sistema nativo do Awetí seja particular, não vamos considerar esta questão aqui, pois estes sons de qualquer maneira necessitam de uma representação na escrita.

Cada consoante é representada por uma letra ou sequência de letras do alfabeto latino: $\left\langle\mathbf{p}, \mathbf{t}, \mathbf{k},{ }^{\prime}, \mathbf{m}, \mathbf{n}, \mathbf{n g}, \mathbf{t s}, \mathbf{z}, \mathbf{g}, \mathbf{h}, \mathbf{w}, \mathbf{j}, \mathbf{r}, \mathbf{l}\right\rangle$, respectivamente. Em especial a oclusiva glotal / $/$ / é representada por um símbolo que tem a mesma forma que o apóstrofo (ver seção 3.5, particularmente a nota de rodapé 19).

A consoante $/ \mathbf{z} \mid$, diacronicamente relacionada a /r/, é particular do Awetí ou pelo menos raro entre as línguas Tupí (ver, p.ex., Rodrigues 1999; Rodrigues \& Cabral 2012: 503ss). O mesmo som aparece, no entanto, na língua vizinha Wauja / Mehinaku (Aruak) do Alto Xingú. Nesta língua, ela é escrita com a letra 〈j〉 (cf. Postigo 2014: 125ss), inclusive no próprio nome do povo: “Wauja" [wa'uzạ] ou até [wa'uza] (o etnônimo em Português era tradicionalmente Waurá). A ortografia aqui proposta não adotou a mesma letra $\langle\mathbf{j}\rangle$ para este som do Awetí, reservando-a para o glide /j/. Esta, por sua vez, não é escrita com $\langle\mathbf{y}\rangle$, inclusive porque o $\langle\mathbf{y}\rangle$ em Awetí representa a vogal /î/, pelas razões dadas acima. Sobre as variantes pré-nasalizadas de /p, t, k, ts/, ver abaixo a seção 5.3, que discute a questão sobre a nasalidade.

\subsection{As consoantes nasais no final da sílaba e do morfema}

As consoantes $/ \mathbf{p}, \mathbf{t}, \mathbf{k} /$ somente aparecem no final da sílaba em final de morfema, depois de uma vogal oral. Nesta posição final, nunca ocorrem depois de uma vogal nasal, mas podem ocorrer antes e/ou depois de vogais nasais quando no início da sílaba, isto é, no início ou meio da palavra. Ao mesmo tempo, as consoantes /m, n, $\mathbf{y} /$ somente aparecem

${ }^{12}$ Não consideramos aqui os arquifonemas $/ \mathbf{P}, \mathbf{T}, \mathbf{K},{ }^{\circ}, \sim /$, cf. Drude (em prep.). Sua inclusão na discussão contribuiria pouco para o entendimento das questões em foco (mas ver as notas de rodapé 13 e 15). 
no final da sílaba depois de uma vogal nasal, e nunca depois de uma vogal oral. (Estas consoantes nasais também podem ocorrer no meio da palavra, e então causam a nasalização da vogal anterior.) Assim, o contraste entre oralidade e nasalidade das consoantes é neutralizado no fim da sílaba ${ }^{13} \mathrm{e}$, por isso, há pelo menos três possibilidades de escrever estas sílabas finais, em particular as consoantes nasais. Uma alternativa é escrever sempre $\langle\mathbf{p}, \mathbf{t}, \mathbf{k}\rangle$, marcando a nasalidade na vogal anterior (com um til). ${ }^{14}$ Uma outra possibilidade é representar a nasalidade na consoante final, usando $\langle\mathbf{m}, \mathbf{n}, \mathbf{n g}\rangle$. Uma terceira opção incluiria a marcação redundante da nasalidade, tanto pelo til quanto pelo $\langle\mathbf{m}, \mathbf{n}\rangle$ ou $\langle\mathbf{n g}\rangle$ final. Assim, a palavra (14) /otãn/ 'corre/correu', com a pronúncia [̃̃ntãn], poderia ser

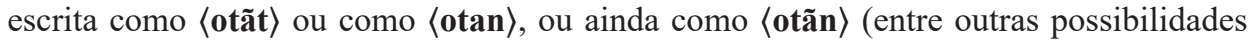
menos óbvias).

Optamos pela segunda possibilidade, especialmente para, sempre que possível, manter a raiz inalterada, apesar de sufixos. Assim, os dois sufixos aspectuais, /-(z))oks/ e /-ju/, não requerem uma mudança na escrita da raiz se esta já termina em /n/: (15) /otãnoks/ 'corria / vai correr' continua otanoko, isto é, otan+oko, e (16) /otãnju/ continua otanju 'está correndo', otan+ju (ver também abaixo, seções 4.4 e 5.3).

\subsection{Lenição}

A consoante /p/, quando fecha a sílaba, pode manifestar-se como o alofone [ $\boldsymbol{\beta}]$, que aparece diante de vogais. Quando esta vogal pertence à palavra seguinte, o /p/ continua

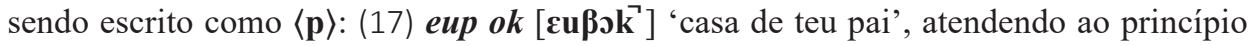
morfemático (da constância da escrita de morfemas). Nestes casos, o fato de que /p/ se encontra no fim da palavra e é seguido por vogal é suficiente para indicar uma pronúncia

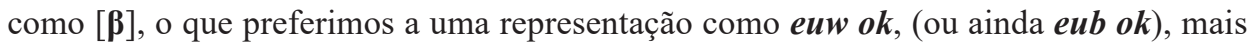
perto da pronúncia. ${ }^{15}$ Contudo, quando este alofone aparece dentro da mesma palavra, escrevemos $\langle\mathbf{w}\rangle$ em vez de $\langle\mathbf{p}\rangle$, a mesma letra da consoante /w/, como em (18) atuwyka /a+tup+ika/ - [atußika] 'não vejo / ví'. O princípio morfemático não pode ser aplicado, neste caso, porque a forma resultante, *atupyka, sugeriria a pronúncia [atupika], com um [p] entre vogais (sem lenição), que também seria fonologicamente possível em Awetí, como por exemplo na forma (19) atupeju - /a+tup+eju/ - [atupeju] 'estou/estava vendo'. ${ }^{16}$

O mesmo acontece com /t/ e /k/: estes têm os alofones lenis $[\mathbf{r}]$ e [ $\mathbf{\gamma}]$, respectivamente, nas mesmas circunstâncias. De novo, na fronteira de palavra a grafia não muda: (20) eywyt

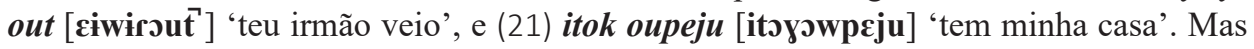

${ }^{13}$ Por este fato, e por causa das lenições (ver abaixo, seção 3.3.), pela análise de Drude (em prep., cf. nota de rodapé 12), podemos aqui postular arquifonemas $/ \mathbf{P}, \mathbf{T}, \mathbf{K} /$, que aparecem somente em codas silábicas. O arquifonema $/ \mathbf{T} /$, por exemplo, tem os alofones $\left[\mathbf{r}, \mathbf{t}^{\top}, \mathbf{n}\right]$.

${ }^{14}$ Isto foi de fato observado diversas vezes, mas inconsistentemente, na escrita espontânea de pessoas sendo alfabetizadas.

${ }^{15}$ De novo, (cf. nota de rodapé 13), temos aqui um arquifonema /P/, com os alofones [ק, $\left.\overrightarrow{\mathbf{p}}, \mathbf{m}\right]$. Por um tempo, consideramos nas discussões de representar estes arquifonemas sempre com uma só letra, por exemplo aqui $\langle\mathbf{b}\rangle$, entre outras opções, mas logo constatamos que isto traria mais problemas do que vantagens.

${ }^{16} \mathrm{Na}$ análise de $\mathrm{S}$. Drude (2011, cf. nota de rodapé 20), temos aqui um fonema abstrato /\%, que impede a lenição, no início do sufixo /-eju/. Ver também abaixo, seção 4.4. 
dentro da palavra, no caso de [r], escrevemos $\langle\mathbf{r}\rangle$ : (22) /i+kit+itu/ - [ikiritu] 'que é verde': ikyrytu, a mesma letra como no caso da consoante / $/$. No caso do $[\mathrm{y}]$ escrevemos $\langle\mathbf{g}\rangle:(23) / \mathbf{t}+\mathbf{a}$ ?ok+itu/ - [ta?oyitu] 'raivoso': ta'ogytu. ${ }^{17}$

\subsection{Palatalização}

Como mostra o exemplo (24) otige [0tfiye] 'sentou', a consoante/t/, diante da vogal/i/, é palatalizada: $[\mathbf{t} \mathbf{f}]$ (semelhante ao que acontece no Português em várias regiões do Brasil). Esta alofonia regular não é representada pela escrita; o /t/ continua sendo representado pela letra $\langle\mathbf{t}\rangle$. Porém, há uma palavra que é uma exceção para esta regra: (25) [mitizịku] 'rezar', sem palatalização (não conhecemos outras palavras com esta propriedade). Para evitar uma leitura como *[mitfiziku], que seria a regular, escrevemos $\langle\mathbf{t h}\rangle$ em lugar do $\langle\mathbf{t}\rangle$ : $\left\langle\right.$ mythizyku〉 'rezar'. ${ }^{18}$

Por outro lado, há algumas poucas palavras em que aparece um [t $\mathbf{f}]$, palatalizado, diante de outras vogais sem ser /i/, como em (26) [mĩntfõntu] 'peidar'. Acreditamos que nestes casos há um /i/ subjacente depois do /t//, que foi ressilabificado e depois se fundiu com a pronúncia palatalizada $[\mathbf{t} \mathbf{f}]$ do $/ \mathbf{t} /$. Consequentemente, escrevemos $\langle\mathbf{t} \mathbf{j}\rangle:\langle\mathbf{m y t j} \mathbf{j} \tilde{\mathbf{t}} \mathbf{t}\rangle$ 'peidar'.

\subsection{A oclusiva glotal / $/$}

Em Awetí, a oclusiva glotal / / é uma consoante plena, contrastando tanto com as outras consoantes como com a ausência de consoantes. Na escrita, ela usualmente é representada pelo símbolo $\langle$ ' $\rangle$. Este é, portanto, uma letra do Awetí. ${ }^{19}$

No meio de raízes e afixos não há motivo para dúvidas: onde há o som [?], há o

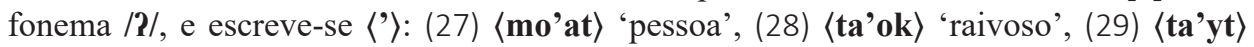
'filho dele' (fala feminina).

Quanto à consoante glotal em posição inicial, porém, há uma situação mais complexa, pois nem todas as glotais fonéticas necessariamente são fonológicas (e nem todas que são possivelmente fonológicas são necessariamente lexicais). Neste caso, precisamos diferenciar entre três grupos de morfemas.

${ }^{17}$ De fato, todos os $\langle\mathbf{g}\rangle$ em Awetí são relacionados a um $/ \mathrm{k} / \mathrm{em}$ final de sílaba (e muitos $\langle\mathbf{r}\rangle$ a um $/ \mathbf{t} /$ ), pelo menos diacronicamente. Mas já começou a se desenvolver uma consoante /y/, em possível contraste com /k/, como na palavra lexicalizada tigap [t/jiyap] 'banco, assento', que originalmente é derivado da raiz/tik/ 'sentar' que ocorre em otige [ot/jiye] 'sentou'.

${ }^{18}$ Essa é a única exceção à palatização de /t/ diante de /i/ que conhecemos, talvez relacionada ao significado da palavra, 'rezar', do campo semântico religioso/espiritual. Como o fenômeno é uma exceção, a regra adotada necessariamente também o é (o único caso de $\langle\mathbf{t h}\rangle$ que conhecemos).

${ }^{19}$ Esta letra é de forma idêntica (ou quase idêntica, dependendo da fonte) com o apóstrofo, mas os dois são funcionalmente diferentes. Portanto, ocupam posições distintas na codificação UNICODE: o apóstrofo comum $\langle '\rangle$ (um símbolo de pontuação), tem o código U+2019 (ou, reto 〈' $\rangle, U+0027$ ), enquanto a letra para a oclusiva glotal $\langle$ ' $\rangle$ tem, em UNICODE, o nome 'modifier letter apostrophe' e o código U+02BC. Sempre quando possível, recomendamos o uso deste último símbolo para a oclusiva glotal, mas o uso, na prática, do apóstrofo também é permitido. No entanto, esta letra do Awetí nunca deve ser escrita como o sinal de citação de abertura, $\left\langle{ }^{6}\right\rangle$, mas sempre com a forma de uma vírgula levantada, $\left\langle{ }^{\prime}\right\rangle$, inclusive e especialmente no início de palavra. 
(1) A maioria dos prefixos e algumas raízes (em particular, de substantivos inalienáveis) na fala cuidadosa não têm e usualmente não permitem a oclusiva glotal quando se coloca algo em sua frente. Nestes casos não escrevemos nunca uma glotal, mesmo que ela possa ser foneticamente inserida em certos contextos em que não há prefixos em frente. Por exemplo: (30) ap 'pelo, cabelinho' (kajap 'nosso pelinho'), (31) op 'folha (de uma planta)' ( $\boldsymbol{n o p}$ 'sua folha'), (32) ok 'casa' (eok 'tua casa'), e também (33) atup ok [atuß ok] 'vi a/ uma casa', embora às vezes isso possa ser realizado com oclusiva glotal: [atup $\mathbf{2} \mathbf{k}$ ].

(2) Algumas outras raízes sempre têm uma glotal, também quando há algo na sua frente (inclusive consoantes). Neste caso, escrevemos sempre a glotal, mesmo quando ela é a primeira letra da palavra: (34) 'ap 'cabelo' (kaj'ap 'nosso cabelo'), (35) 'akympu 'afogar'

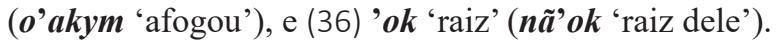

(3) Muitos substantivos alienáveis começam por uma vogal que, na fala, pode ser ou não precedida por uma oclusiva glotal fonética, como (37) [ĩnĩ ?ĩnĩ] 'rede', como em (38) [atuß ĩnĩ] 'vi a/uma rede', também possivelmente com oclusiva glotal: [atup Pĩnĩ]. Quando ocorrem prefixos que marcam a pessoa (esta usualmente se refere a um possuidor), aparece uma glotal entre essa vogal e o / $/$ / do prefixo que marca posse alienável, como em (39) [ĩnt宅ĩnñ] 'minha rede'. Neste caso, acreditamos que a análise mais adequada é que a glotal faz parte do prefixo de posse alienável, o qual tem um alomorfe / $\mathbf{\varepsilon} /$ diante de vogais. Portanto, quando o substantivo ocorre sem prefixos pessoais, não escrevemos a glotal, como em ini 'rede'. Com prefixos pessoais ocorre o prefixo $\langle\mathbf{e}$ ' $\rangle$ e, consequentemente, aparece a oclusiva glotal, como em ite' iñ̃ 'minha rede'. Quando há perigo de se confundir uma palavra alienável com uma outra, inalienável, podemos, apesar da regra agora descrita, escrever a glotal, como no caso de (40) 'op 'folha (de papel), documento, livro, dinheiro' (alienável, cf. ne'op 'papel dele/dela'), que contrasta com (41) op 'folha (da planta)' (inalienável, cf. nop 'sua folha').

Estamos cientes que estas distinções requerem uma certa compreensão de conceitos sintáticos avançados, o que pode posar problemas para alguns alunos; e de fato, observamos que estas regras não estão sendo empregadas com muita consistência, assim que por vezes se omite a oclusiva glotal na escrita no início de palavras. Aparentemente, a probabilidade de isso causar confusão na compreensão é menor do que o esforço necessário para aplicar estas regras com consistência. Portanto, numa futura revisão, é possível que estas regras mudem, liberando a omissão de $\langle$ ' $\rangle$ no início da palavra à critério dos escritores.

\subsection{Metátesis da oclusiva glotal}

Em algumas palavras compostas, onde se encontra uma consoante final (lenis) com uma oclusiva glotal inicial (de uma raiz do tipo (2), acima), há a possibilidade de metátesis, ou seja, a oclusiva glotal se manifesta antes da consoante, como em (42) / kwat+?ip/ [kwa?rip? kwar?ip'] 'festa do Kuarup', ou (43) /o+kãm+?u/ [̃̃̄kãm?ũ ว̃kã?mũ] 'bebe(m) leite do peito'. Neste caso recomendamos seguir, na escrita, a ordem subjacente, ou seja, colocar a glotal depois da outra consoante: $\boldsymbol{k w a r} \boldsymbol{y} \boldsymbol{y}, \boldsymbol{o k a m}$ ' $\boldsymbol{u}$. 


\section{DRUDE, W. AWETE e A. AWETI - A ORTOGRAFIA DA LÍNGUA AWETÍ}

\section{Considerações sobre afixos e partículas específicos}

\subsection{Prefixos com oclusiva glotal}

Alguns prefixos, em particular de segunda pessoa, começam por uma oclusiva glotal:

(44) $/ \mathbf{R} \boldsymbol{\varepsilon} / \quad 2^{\mathrm{a}} \mathrm{Sg} . \quad(45) / \mathbf{R} \boldsymbol{\varepsilon} \mathbf{i} / \quad 2^{\mathrm{a}} \mathrm{Pl}$.

É possível verificar esta oclusiva glotal pelo fato de que usualmente não ocorre a lenição de oclusivas finais da palavra anterior. Especialmente no caso do prefixo da segunda pessoa singular, há possibilidade de se confundir a forma com e a forma sem a oclusiva glotal, como no caso de:

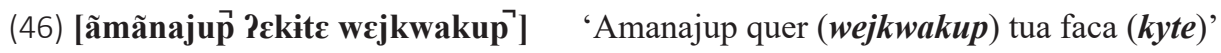

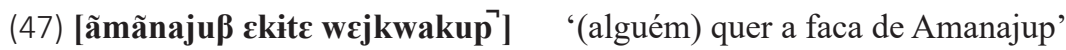

Por estas observações, e especialmente pela possibilidade de confundir as formas, acreditamos que seja indicado escrever a letra $\left\langle{ }^{\prime}\right\rangle$ no início da palavra quando um dos prefixos da segunda pessoa está presente, em nomes, verbos nominalizados ou com o sufixo -tu, e posposições, mas não no caso de verbos comuns, onde não há perigo de confusão. Por exemplo, escrevemos (48) 'e'ikyte 'faca de vocês', (49) 'etotu 'que você foi / tua ida', mas (50) eto 'você foi', (51) 'ekyte 'tua faca', mas (52) ... ekyte 'faca de ...'. Em todos os outros casos de prefixos, não se escreve a oclusiva glotal no início da palavra, apesar de que os falantes podem inseri-la na fala (apenas foneticamente ou por causa de fatores de ordem sintática).

De novo vale aqui que na prática se mostrou que a escrita da oclusiva glotal não está sendo aplicada com muita consistência e que as regras podem precisar de revisão.

\subsection{Pronomes}

Observações semelhantes às dadas na seção anterior valem para os dois pronomes da segunda pessoa, relacionados formalmente com os prefixos. Os aprendizes da escrita Awetí frequentemente vinham com a dúvida sobre se deveriam escrever ou não uma oclusiva glotal nestes pronomes, já que a glotal está obrigatoriamente (e, portanto, fonologicamente) presente e é claramente percebida. Decidimos que a glotal deve ser representada na escrita:

(53) /Pعn/ 'en 2a Sg, 'tu / você'

(54) /REPipe/ 'e’ipe 2a Pl, 'vos / vocês'

Como no caso dos prefixos, esta decisão era a mais recente no estabelecimento das regras ortográficas, e ainda tinha que ser consolidada na prática e na sala de aula (com resultados variados, ver acima). Assim, no corpus de textos existentes (cf. Drude; Reiter \& Lieb 2006), podem ser encontrados muitos exemplos em que estas formas (inclusive os prefixos pessoais) estão escritas sem a glotal inicial. Os demais pronomes pessoais não 
têm oclusiva glotal inicial fonológica: (55) atit 'eu' (fala masculina), (56) ito 'eu' (fala feminina), (57) $\tilde{\boldsymbol{i}}$ 'ele/ela' (fala feminina), (58) kajã 'nós (inclusive você)', (59) azoza / ozoza 'nós (sem você)', (60) $\boldsymbol{t} \boldsymbol{a}$ 'i 'eles/elas' (fala feminina).

Outros pronomes que merecem uma atenção especial, somente na variedade da fala masculina, são os pronomes dêiticos e os pronomes pessoais de terceira pessoa (singular e plural). Se estes pronomes ocorrem diante das partículas (61) $\boldsymbol{a}^{\prime} \boldsymbol{y} \boldsymbol{n}$ e (62) $\boldsymbol{a}^{\prime} \boldsymbol{y} \boldsymbol{t}$ em particular, ocorre um $/ \mathbf{n} /$ entre estas duas palavras. A questão é a qual palavra este $/ \mathbf{n} /$ pertence.

Como o /n/ pode também ocorrer diante de certas posposições que começam com vogal, somente com estas mas não com outras palavras que terminam com vogal (p.ex. tsãn eze 'misturado com eles', mas 'y eze 'misturado com agua', não *'yn eze), e como a nasalidade é característica de apenas uma das partículas, mas está presente em todos os pronomes em questão (comportando-se de forma peculiar), optamos por atribuir o /n/ aos pronomes, os quais têm, então, duas formas (determinadas pelo contexto). Apesar da presença do /n/, que já implica a nasalidade da vogal anterior, mantemos o til em cima do /a/, para facilitar a identificação do pronome em questão (seguindo o princípio morfemático, assim que, por exemplo, $\boldsymbol{n} \tilde{\boldsymbol{a}}$ é sempre escrito $\boldsymbol{n} \tilde{\boldsymbol{a}}$, e não algumas vezes $\boldsymbol{n} \tilde{\boldsymbol{a}}$ e outras $\boldsymbol{n} \boldsymbol{a} ;$ e analogamente para $\boldsymbol{t s} \tilde{\boldsymbol{a}}$ e para as formas com ...t $\tilde{\boldsymbol{a}}$ ).

\begin{tabular}{|c|c|c|c|}
\hline (63) $\boldsymbol{n \tilde { a }} / \boldsymbol{n} \tilde{a} \boldsymbol{n}$ & 3Sg, 'ele / ela' & (64) $t \mathbf{s} \tilde{a} / t \mathbf{t} \tilde{a} n$ & 3P1, ‘eles / elas' \\
\hline 5) jatã / jatãn & 'este / esta' & (66) kujtã / kujtãn & 'aquele / aquela' \\
\hline 7) kitã / kitãn & 'esse / essa' & (68) itã / itãn & (partícula de topicalização) \\
\hline
\end{tabular}

\subsection{Partículas e posposições que começam com glotal}

Algumas partículas começam sempre com uma oclusiva glotal. Por isso, há muito tempo concordamos em escrevê-las com a glotal inicial. Já no caso de posposições, a grafia delas segue os princípios para as palavras do grupo (2) em seção 4.3.

Seguem as partículas e posposições frequentes que pertencem a este grupo:

(69) 'yto 'então', (70) 'ytoto 'verdadeiramente, muito', (71) 'apo 'sobre', (72) 'ywo 'com, acompanhando (pessoa)', (73) 'a, (74) 'ẽ (estas partículas de final de sentença possivelmente indicam um grau elevado de envolvimento emocional do falante; ' $\boldsymbol{a}$ é utilizada somente por homens).

\subsection{Sufixos com uma oclusiva}

Falamos na seção 3.3, acima, sobre o processo de lenição de consoantes no fim do morfema diante de vogais (e raras vezes diante da oclusiva glotal). Este processo ocorre na fronteira de palavras (onde a escrita mantém a grafia da consoante não-lenizada) e em caso de composição e diante de certos sufixos, como (75) oko '(imperfectivo)' (76) e'ym '(negação nominal)', (77) (z)an '("na função de")' (78) eju '(ingressivo)' (em caso de verbos estativos), e outros. Há, porém, alguns sufixos onde essa lenição não ocorre: 
(79) -(t)u'(subjuntivo, nominalização verbal)', (80) -ap '(nominalização de instrumento / lugar)', (81) -at, '(nominalização de sujeito)', (82) -aw, '(gerúndio)', (83) -(e)ju '(progessivo)' (em caso de verbos ativos). Diante destes sufixos, as consoantes /p, t, k/ ocorrem em suas variantes fortes $[\mathbf{p}, \mathbf{t}, \mathbf{k}]$. Na fala (no nível fonético), entre as consoantes /m, n, $\mathbf{\eta}, \mathbf{w}, \mathbf{j}$ / e estes sufixos ocorrem consoantes oclusivas homorgânicas, resultando nas sequências [mp, nt, $\mathbf{n k}, \mathbf{w p}, \mathbf{j t}]$, respectivamente.

$\mathrm{Na}$ ortografia, estas consoantes 'adicionais' são representadas pelas letras $\langle\mathbf{p}, \mathbf{t}, \mathbf{k}\rangle .^{20}$ Como é mencionado abaixo na seção 5.3, estes são casos em que encontramos, na escrita, as sequências $\langle\mathbf{m p}, \mathbf{n t}, \mathbf{n g k}, \mathbf{w p}, \mathbf{j t}\rangle$, e ainda a sequência $\langle\mathbf{n j}\rangle$. As células da seguinte tabela contêm, na sua representação ortográfica, os respectivos resultados da combinação de um morfema que termina no elemento à esquerda de cada linha com o sufixo no topo de cada coluna ("V" representa qualquer vogal; observar a interação 'irregular' do sufixo $j u$ com um /t/, /n/ ou /j/ final, sublinhado, p.ex.: (84) otet 'dorme/dormiu' vs. (85) oteju 'está/ estava dormindo $\left.{ }^{21}\right)$ :

\begin{tabular}{|c|c|c|c|c|c|}
\hline & $-(t) u$ & $-a p$ & $-a t$ & $-a w$ & $-(\boldsymbol{e}) \boldsymbol{j} u$ \\
\hline$\ldots V$ & ...Vtu & ..Vap & ...Vat & $\ldots V a w$ & $\ldots V j u$ \\
\hline$\ldots p$ & $\ldots p u$ & ...pap & ...pat & $\ldots p a w$ & ...peju \\
\hline$\ldots t$ & $\ldots t u$ & ...tap & ...tat & $\ldots t a w$ & $\ldots \dot{\mu j u}$ \\
\hline ...k & $\ldots k u$ & ...kap & ...kat & $\ldots k a w$ & ...keju \\
\hline ...m & ...mpu & ...mpap & ...mpat & ...mpaw & ...mреји \\
\hline ...n & ...ntu & ...ntap & ...ntat & ...ntaw & $\ldots n j u$ \\
\hline ...ng & ...ngku & ...ngkap & ...ngkat & ...ngkaw & ...ngkeju \\
\hline$\ldots W$ & $\ldots w p u$ & ...wpap & ...wpat & $\ldots w p a w$ & ...wpeju \\
\hline$\ldots \mathrm{j}$ & ...jtu & ...jtap & ...jtat & ...jtaw & $\ldots j u$ \\
\hline
\end{tabular}

\subsection{A partícula me}

A partícula (86) $\boldsymbol{m} \boldsymbol{e}$ (de significado incerto), ocorrendo no final da maioria das frases em Awetí, interage com a última consoante da palavra anterior - esta é foneticamente nasalizada, enquanto a consoante inicial da partícula me se adapta, no seu ponto de articulação, à consoante anterior. O resultado na fala é uma só consoante nasal. De novo, observando o princípio morfemático, a ortografia mantém a grafia da consoante final da palavra anterior, mas representa a consoante resultante na partícula. No caso das semivogais /w/ e /j /, estes aparecem também na partícula, que recebe o til, que de outro modo não é escrito na partícula, já que a vogal da partícula usualmente não manifesta nasalidade. Portanto, as representações fonéticas e escritas são ("V" representa novamente qualquer vogal):

\footnotetext{
${ }^{20}$ Numa análise mais sistemática, são alofones do fonema abstrato /\%, ver acima nota de rodapé16.

${ }^{21}$ Logo concordamos que a grafia sugerida pelo princípio morfemático, *otetju, teria mais desvantagens que vantagens.
} 


\begin{tabular}{|c|c|c|c|c|c|}
\hline$\ldots V p$ & {$[\ldots V m \varepsilon]$} & $\ldots V p$ me & $\ldots V m$ & {$[\ldots \tilde{\mathbf{V}} \mathbf{m} \varepsilon]$} & $\ldots V m$ me \\
\hline$\ldots V t$ & [...Vne] & ...Vt ne & $\ldots V n$ & {$[\ldots \tilde{V} n \varepsilon]$} & ...Vnne \\
\hline ...Vk & {$[\ldots V \eta \varepsilon \varepsilon]$} & ...Vk nge & $\ldots V n g$ & {$[\ldots \tilde{V} \eta \varepsilon \varepsilon]$} & $\ldots V n g n g e$ \\
\hline $\begin{array}{l}\ldots . . V w \\
\ldots V\end{array}$ & $\begin{array}{l}{[\ldots V w \tilde{\varepsilon}]} \\
{[\ldots V m \varepsilon]}\end{array}$ & $\begin{array}{l}\ldots V w w \tilde{e} \\
\ldots V m e\end{array}$ & $\ldots V j$ & {$[\ldots V \mathbf{j} \tilde{\varepsilon}]$} & $\ldots V \boldsymbol{j} j \tilde{\boldsymbol{e}}$ \\
\hline
\end{tabular}

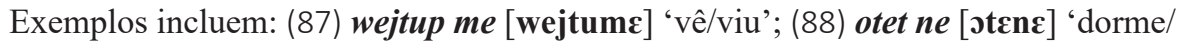

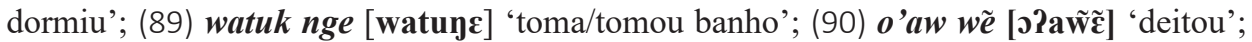

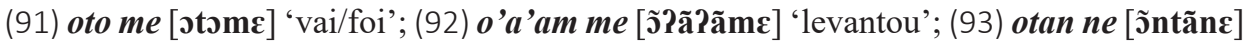

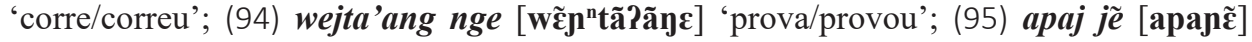
'papai!'.

A principal razão para optar por esta regra foi evitar formas homógrafas, mesmo que isso implique em que consoantes orais, presentes na escrita, não sejam pronunciados. Assim, temos (96) atak nge 'chorei' vs. (97) atang nge 'coloquei (dentro)', que ambos têm, na pronúncia, somente um $[\boldsymbol{\eta} \varepsilon]$ no final. No entanto, neste caso as expressões não são homófonas: [atang] vs. [ãntãy $\varepsilon$ ], e o $\langle\mathbf{k}\rangle$ em atak nge indica esta pronúncia oral - outra vantagem de mantê-lo na escrita.

\section{A representação da Nasalidade}

\subsection{Regras e representação básicas}

Em Awetí ocorre harmonia nasal (cf. Drude 2009), ou seja, um elemento intrinsecamente nasal causa a nasalização fonética de outros segmentos (no caso do Awetí, usualmente à sua esquerda), fazendo com que a nasalidade possa se estender através de várias sílabas na palavra. Se a nasalidade está presente em uma palavra, a ortografia procura marcá-la somente uma vez. Isto quer dizer que, na leitura, a presença de um elemento nasal implica, à sua esquerda, na nasalização dos segmentos passíveis de nasalização. Assim, os alofones nasais de segmentos nasalizáveis não seriam distintos, pela ortografia, dos alofones orais.

Os únicos casos em que pode haver duas vezes a marcação de nasalidade na mesma palavra envolvem composições, ou um dos prefixos (98) $\boldsymbol{n} \tilde{a}$ - ou (99) $\tilde{\boldsymbol{i}}$ - 'ele/ela' (na fala masculina ou feminina, respectivamente, cf. Drude 2002). De acordo com o princípio morfemático, estes exemplos sempre mantêm o til, mesmo em contexto nasal (se (100) ts $\tilde{\boldsymbol{a}}$ 'eles/elas' é considerado prefixo, o mesmo princípio deve ser aplicado). Há perigo de se confundir, em particular, o prefixo $\boldsymbol{n} \tilde{\boldsymbol{a}}$, com til, com casos em que a variante $\boldsymbol{n}$ do mesmo prefixo aparece diante de uma raiz que começa por /a/. É necessário determinar qual é a raiz da palavra em questão, observando outras formas, como a da primeira ou segunda pessoa singular.

Exemplo: (101) na'ang [nã?ãy] 'desenho/imagem dele/dela' (cf. ita'ang [ĩntã?ãy] 'minha imagem', raiz: a'ang), contrastando com o homófono: (102) nãa'ang [nã?ãy] 'sombra dele/dela' (cf. i'ang [ĩ̃ãu] 'minha sombra', raiz: 'ang). 


\subsection{Vogais}

As vogais intrinsecamente orais não recebem marcação ortográfica especial; em casos de necessidade de marcação de acento, receberiam o acento grave: $\langle\grave{a}\rangle$ etc. ${ }^{22}$ Já as vogais intrinsecamente nasais são usualmente marcadas pelo til: $\langle\tilde{\mathbf{a}}, \tilde{\mathbf{e}}, \tilde{\mathbf{i}}, \tilde{\mathbf{o}}, \tilde{\mathbf{u}}, \tilde{\mathbf{y}}\rangle$. (Se não for possível usar o til por alguma razão técnica, é recomendado o uso do trema $\langle\ddot{a}, \ddot{e}, \mathbf{i}, \ddot{\mathbf{o}}$, $\ddot{\mathbf{u}}, \ddot{\mathbf{y}}\rangle$ para marcar a nasalidade.) Se a vogal se encontra em sílaba fechada por consoante oclusiva, esta consoante será representada por $\langle\mathbf{m}, \mathbf{n}, \mathbf{n g}\rangle$ (ver a seção 3.2). Neste caso, a marcação da vogal nasal com o til não é necessária, inclusive se a raiz é seguida por afixos facilmente reconhecíveis (ver abaixo, nas seções sobre o acento, 6.2 e 6.3, para listas e exemplos).

As vogais sem nasalidade ou oralidade intrínseca não são marcadas (semelhante às vogais intrinsecamente orais). Na leitura, uma vogal pode e deve ser pronunciada como nasalizada se, na mesma palavra simples, ela é seguida, imediatamente ou com outras letras intermediárias, por uma vogal com til, ou por uma das letras $\langle\mathbf{m}, \mathbf{n}\rangle$, ou o dígrafo $\langle\mathbf{n g}\rangle$. Em composições, que os falantes identificam sem dificuldade, cada parte é um domínio separado para a nasalidade/oralidade.

\subsection{Consoantes}

As consoantes intrinsecamente nasais são $/ \mathbf{m}, \mathbf{n}, \mathbf{y} /$, representadas por $\langle\mathbf{m}, \mathbf{n}, \mathbf{n g}\rangle$, respectivamente. A grande maioria das outras consoantes têm uma variante fonética oral e uma variante nasalizada, que não são diferenciadas na escrita. Na leitura, uma consoante deve ser pronunciada nasalizada nas mesmas circunstâncias das vogais (quando tem um elemento nasal à sua direita).

Em particular, as variantes pré-nasalizadas $[\mathbf{m p}, \mathbf{n t}, \mathbf{n k}, \mathbf{n t s}]$ das oclusivas $/ \mathbf{p}, \mathbf{t}, \mathbf{k} / \mathrm{e}$ da africada /ts/, respectivamente, são escritas como $\langle\mathbf{p}, \mathbf{t}, \mathbf{k}, \mathbf{t s}\rangle$ e não como $\langle\mathbf{m p}, \mathbf{n t}$, ngk, nts). No entanto, como foi mencionado na seção 4.4., estas últimas sequências de letras podem aparecer, mas somente quando uma consoante oclusiva em final de sílaba (o último segmento de uma raiz ou um sufixo) se encontra diante de sufixos ou outras raízes que começam com uma oclusiva, em particular, as variantes dos sufixos -(t) $\boldsymbol{u},-\boldsymbol{a p}, \boldsymbol{- a t}, \boldsymbol{- a} \boldsymbol{w}$, (e)ju: (103) ko'empu (ko'em+pu, 'o amanhecer'), (104) tantat (tan+tat, 'quem corre'), (105) o'apazungkeju (o+'apazung+keju, 'está se deitando'). Neste caso, mais uma vez, o princípio morfemático determina que não haja uma representação puramente segmental.

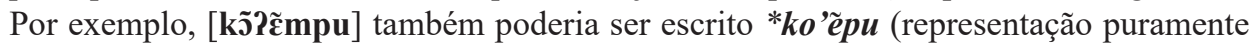
segmental), mas a raiz $\boldsymbol{k o}^{\prime} \mathbf{e m}$ se mantem inalterada na grafia estabelecida: $\boldsymbol{k o}^{\prime} \mathbf{e m p u}$.

Há muito poucos casos em que a variante nasal da semivogal /j/ é marcada na escrita pela sequência de letras $\langle\mathbf{n} \mathbf{j}\rangle$. Isto acontece particularmente na palavra com a raiz

${ }^{22}$ As únicas palavras onde isto foi considerado são os pronomes demonstrativos, na fala masculina, que

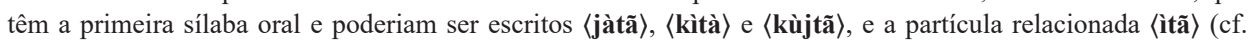
seção 4.2). Porém, essas formas são tão poucas, tão frequentes e de tão fácil identificação que a marcação não parece necessária. 
(106) njyt [nit ] 'irmã (do homem)', como em injyt 'minha irmã' (diz um homem), enjyt 'tua irmã', etc. ${ }^{23}$

Quando o sufixo -ju '(progressivo)' ocorre depois de uma raiz que termina em $/ \mathbf{n} /$, também ocorre a mesma sequência $\langle\mathbf{n j}\rangle$ na grafia, onde, na fonética, também temos o som nasal palatal [n]. Isto se deve, mais uma vez, ao princípio morfemático. Por exemplo, escrevemos (107) 〈otanju〉 'está/estão correndo' de o- $\tan$-ju (/o+tãn+ju/) com a

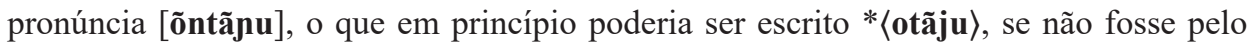
fato de o sufixo $\boldsymbol{j} \boldsymbol{u}$ ocorrer aqui depois de uma raiz que termina em $\langle\mathbf{n}\rangle$, e esta raiz, tan, se mantém inalterada na escrita. ${ }^{24}$

\section{Palavras e acentos}

\subsection{Considerações gerais}

Logo nos primeiros anos da nossa colaboração decidimos não usar diacríticos em Awetí a não ser o til que marca nasalidade (ver acima, seção 5.2), mas não necessariamente a sílaba acentuada. Em discussões que antecederam a elaboração da primeira versão deste texto, em 2006-2008, voltamos a considerar a possibilidade de introduzir, em algum momento no futuro, diacríticos como o acento agudo $\langle$ ' $\rangle$ ou grave 〈'〉. Porém, por enquanto não temos certeza em que circunstâncias isto seria indicado e qual seria a necessidade, pois a sílaba tônica é previsível em quase todas as formas de palavras que ocorrem em textos escritos em Awetí. Em palavras simples sem sufixos, o acento usualmente ocorre na última sílaba da raiz, com poucas exceções. Por exemplo, há vários casos em que parece haver mais do que uma sílaba tônica na mesma palavra, ou ao mesmo tempo, ou com oscilação do acento entre as sílabas em questão de enunciado a enunciado. ${ }^{25}$

Portanto, mesmo que isto não seja parte, estritamente falando, da ortografia (mas sim, das regras de como ler o Awetí), vamos em seguida classificar os sufixos e as partículas conforme suas propriedades de atrair ou admitir o acento tônico. (Por acento tônico, entendemos, aqui, a proeminência na fala de uma sílaba dentro de uma palavra fonológica, indicando sua capacidade de nela se manifestar uma acentuação sintática, como um acento contrastivo). Também, no final desta seção, esclarecemos as regras para a separação ou junção de unidades em palavras ortográficas.

${ }^{23}$ Esta grafia também reflete que esta palavra provavelmente é produto de uma ressilabificação de uma forma subjacente como /niit/ (semelhante ao caso do /t/ palatalizado [t $\mathbf{t}$ ] diante de outras vogais sem ser /i/, ver seção 3.4).

${ }^{24}$ De fato, a forma 〈otãju〉, que tem a mesma pronúncia que 〈otanju〉, existe também em Aweti e significa 'está/estão esperando', de tãtu, 'esperar', raiz: tã . De novo, o princípio morfemático ajuda distinguir, na escrita, formas homófonas.

${ }^{25}$ Para um estudo detalhado, ver Drude (2011), onde também se analisa a manifestação concreta do acento (mais no contorno do pitch do que na intensidade ou no alongamento). 


\subsection{Sufixos que atraem $o$ acento}

Poucos sufixos mudam a posição do acento tônico para a direita quando são combinados com uma raiz (ou uma palavra que já contém um outro sufixo). O sufixo do progressivo (e)ju é um exemplo disto: quando ele aparece na sua variante $\boldsymbol{e j} \boldsymbol{j}$ - tanto com verbos ativos, onde aparece uma consoante oclusiva diante do /e/ (ver seção 4.4), quanto com verbos estativos, onde ocorre lenição (ver seção 3.2). Nos dois casos, o acento tônico recai sobre a sílaba que contém o/ع/ do sufixo. Outros sufixos que atraem o acento são -tut 'querer' e -(p)ut 'passado nominal'.

Indicamos, a seguir, a sílaba tônica, sublinhando a vogal em questão.

(108) $\boldsymbol{e} \boldsymbol{j} \boldsymbol{u}$ (com verbo estativo): ita' $\underline{\boldsymbol{\alpha}} \boldsymbol{k}$ 'estou/estive com raiva' - ita' 'oge $\boldsymbol{j} \boldsymbol{u}$ 'estou ficando com raiva';

(109) $\boldsymbol{e j u}$ (com verbo ativo): ajatuk 'tomo/tomei banho' - ajatukeju 'estou tomando banho'.

(110) tut (usualmente com ju: tuju): ajatuk 'tomo/tomei banho' - ajatuktuju 'quero tomar b.'

(111) ut: itok ' 'minha casa' - itog $\underline{u}$ ' 'minha antiga casa'.

\subsection{Sufixos que não atraem 0 acento}

A grande maioria dos sufixos (que, de qualquer maneira, não são muitos em Awetí) não altera a posição do acento. Na leitura, quando se identifica a presença de um ou vários destes sufixos, significa que o acento continua na mesma sílaba tônica que sem o sufixo; usualmente, na última sílaba da raiz (ou em sílaba de um sufixo tônico, ver a seção anterior). A lista de sufixos com esta propriedade inclui:

(112) -ap '(nominalização de instrumento / lugar)', (113) -at '(nominalização de sujeito)', (114) -aw '(gerúndio)', (115) -e'ym '(negação nominal)', (116) -ju '(progessivo)' (na variante sem /ع/), (117) -ka/yka '(negação verbal)', (118) -(y)pe '(locativo)', (119) -(t)u '(subjuntivo, nominalização verbal)', (120) -(y)wo '(locativo difuso)', (121) -ytu '("o que é...”)', (122) -za '(grupal)', (123)-(z)an '(essivo)', (124) -(z)oko '(imperfectivo)'.

\section{Exemplos:}

(125) -(z)oko: ajatuk 'tomo banho' - ajatugoko 'eu tomava banho / continuo tom. banho'.

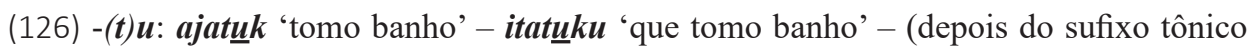
-(e)ju:) itatukejutu 'que estou tomando banho'.

(127) -(z)oko e -(t)u: ajatuk 'tomo banho' - itatugokotu 'que eu tomava banho / que continuo tomando banho'. 


\subsection{Partículas que levam acento}

As palavras não-flexionáveis, comumente chamadas de 'partículas', também se diferenciam por terem ou não a capacidade de carregar acentuação sintática. Algumas partículas contêm sílabas que são 'tônicas' neste sentido, isto é, sílabas que são salientes na sentença e podem carregar acentuação sintática. Este grupo inclui partículas sentenciais (que podem ser enunciadas sozinhas): (128) a $\underline{\boldsymbol{n}}$ 'não', (129) $\boldsymbol{e} \boldsymbol{h} \underline{\tilde{e}}$ 'sim', (130) wa $\underline{\boldsymbol{a}}$ 'e então? (para perguntas)', várias partículas 'de segunda posição' (ou que seguem as palavras que elas modificam): (131) etsann '("temporariamente, provisoriamente”)', (132) tepe

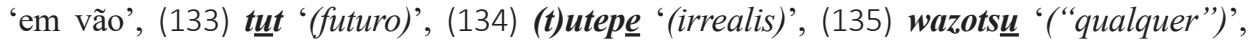
(136) wene '("ainda")', (137) wezanu 'de novo', (138) wezotsu 'somente', (139) wịan '("temporariamente")', (140) 'yto 'então', (141) 'ytoto 'verdadeiramente, muito', (142) zots $\underline{u}$

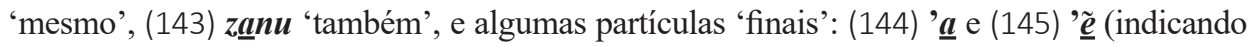
um grau elevado de envolvimento emocional do falante), (146) $\boldsymbol{m} \underline{\underline{e}}$ (sem tradução clara), e a partícula (147) $\boldsymbol{k} \boldsymbol{g} \boldsymbol{j}$ 'ao que parece' (sem posição fixa).

\subsection{Partículas que não levam acento}

Outras partículas parecem não poder receber acentuação sintática, ou seja, não contêm nenhuma sílaba tônica. Quanto ao acento, estas partículas se comportam como clíticos (dependem de uma palavra, usualmente a anterior, que tem uma sílaba tônica). A lista destas partículas inclui várias partículas 'de segunda posição' na frase: (148) a'yt (indica empatia ou até compaixão do falante), (149) ti 'dizem que' (evidencial), (150) tuti e (151) weti 'para que não', e algumas partículas 'finais': (152) a'yn (sem tradução clara) e (153) ika 'aparentemente'.

\subsection{Palavras ortográficas}

As listas acima, bastante exaustivas, de sufixos e partículas também são úteis para determinar as fronteiras de palavras (gramaticais) da língua. Em geral, a escrita respeita esta diferença entre palavras e afixos, ou seja, cada um dos sufixos acima mencionados se escreve junto com a raiz da palavra (ou outro sufixo), enquanto as partículas são separadas da palavra anterior por um espaço, até mesmo as partículas clíticas listadas na seção 6.5.

O mesmo vale para as posposições, apesar de elas não terem autonomia sintática (não podendo ocorrer sem uma palavra complemento ou um prefixo na sua frente). ${ }^{26}$ Posposições, gramaticalmente, são palavras independentes e na escrita são separadas da palavra anterior (inclusive quando aparecem na variante com um $\boldsymbol{y}$ inicial para evitar o encontro entre duas consoantes):

(154) Awajurupa kyty 'para Awajurupá', (155) me ywãa 'ao longo do caminho'.

\footnotetext{
${ }^{26}$ As posposições se diferenciam de alguns poucos sufixos de caso (-wo '(locativo, instrumental)' ou -pe '(locativo, dativo)'). Estes não têm autonomia fonológica: o acento recai na raiz da palavra antes do sufixo, como em ogywo 'na casa'.
} 
Os prefixos de pessoas de substantivos (que indicam posse ou uma outra relação

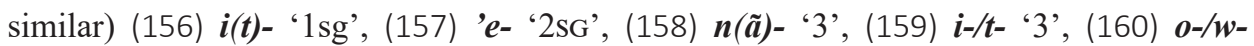
'3REFL', (161) kaj- '1+2PL', (162) azo-/ozo- '112PL', (163) 'e'i- '2PL' são escritos juntos: (164) kajti 'nosso bico' (também para a região do corpo humano ao redor da boca), e o mesmo vale para os prefixos verbais (165) $\boldsymbol{a}(\boldsymbol{t})-$ ' $1 \mathrm{sG}$ ', (166) ' $\boldsymbol{e}(\boldsymbol{t})$ - '2 $2 \mathrm{sG}$ ', (167) jo(t)- e (168) $\boldsymbol{i}$ - '2SG.IMP', (169) o-/w- '3', (170) $\boldsymbol{w e j}(\boldsymbol{t})$ - '3', (171) $\boldsymbol{t i}(\boldsymbol{t})-$ ' $1+2 \mathrm{PL}$ ', (172) azoj(t)-/ $\boldsymbol{o z o j}(\boldsymbol{t}) 1 \backslash 2 \mathrm{PL}$ ', (173) pej(t)- '2PL' (listando somente os que têm uma forma diferente dos prefixos de posse), e ainda para prefixos que ocorrerem entre estes prefixos de pessoa e a raiz, como a marca para causativização (174) $\boldsymbol{m o}$-/w-, para o comitativo (175) (z)e(z)-/ $\boldsymbol{z o -}$, o reflexivo (176) te-, o recíproco (177) to-, o nominalizador de objeto (178) $\boldsymbol{m} \tilde{\boldsymbol{\imath}}$, , e o 'antipassivo' (179) po(r)-.

Quando as posposições recebem a marcação de pessoa (inclusive o prefixo da terceira pessoa do singular, (180) $\boldsymbol{n} \tilde{\boldsymbol{a}}-$, na fala masculina, e (181) $\tilde{\boldsymbol{u}}$, na fala feminina, igual aos pronomes da terceira pessoa singular), estas marcas são prefixos e devem ser escritos juntos com a posposição - somente poucas posposições, como (182) $\boldsymbol{t a}$ ' 'com', não levam estes ou qualquer outros prefixos, e neste caso ocorrem os pronomes plenos de pessoa, que são escritos separados:

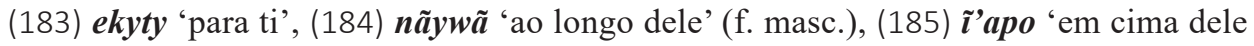
(f. fem.)', mas (186) 'en ta 'contigo'.

Um caso ambíguo são os elementos que marcam a terceira pessoa do plural, $\boldsymbol{t} \boldsymbol{s} \tilde{\boldsymbol{a}} \mathrm{e} \boldsymbol{t a} \boldsymbol{i} \boldsymbol{i}$ respectivamente na fala dos homens $(\widehat{\phi})$ e das mulheres ( $(+)$. Resolvemos, provisoriamente, de tratá-los como um pronome independente e, portanto, de escrevê-los separadamente da posposição, igual aos pronomes demonstrativos:

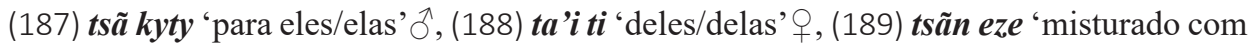
eles/elas' ${ }^{7} .{ }^{27}$

Só no caso de lexicalizações cabe escrevê-los como uma só palavra ortográfica:

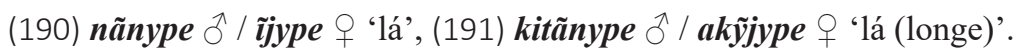

O mesmo vale para a diferença entre composições e construções sintáticas ('genitivas'). Estas são difíceis de se distinguir em Awetí. A ortografia, portanto, recomenda escrever dois substantivos separados quando em construção genitiva, a não ser que se trate de lexicalização, a qual é escrita em uma só palavra (um critério para isto é que o sentido da construção não é previsível a partir dos sentidos das duas palavras que a compõem). Se ocorrer o prefixo de posse alienável $\boldsymbol{e}$ (ou sua variante $\boldsymbol{e}$ ' diante de vogais), este é escrito junto com a palavra à direita (ver seção 3.4 , ponto (3)):

${ }^{27}$ Mas há as formas dos pronomes com sufixo de caso, como em tsãpe 'a eles', kitãpe 'para este'. 
(192) Karitu ok 'casa de Karitu”, (193) muzak tĩ 'bico do pássaro', (194) kujãkyt ekyte 'a faca da menina', (195) kaminu'at e'inĩ 'a rede do menino', mas: (196) mani'oky 'perereba' (uma bebida doce feito da água que sobra de lavar a mandioca ralada; palavra originalmente composta de (197) mani'ok 'mandioca' e (198) 'y ‘água').

Se a segunda palavra numa construção for um verbo (nominalizado ou com $(\boldsymbol{t}) \boldsymbol{u}$ ), o complemento que o precede ('absolutivo', ou seja, o sujeito no caso de verbos intransitivos, mas o objeto no caso de verbos transitivos) será escrito separadamente:

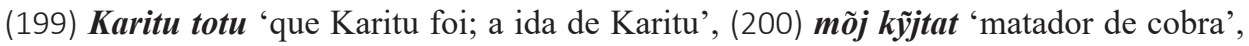
(201) mo'at emĩtup 'o que foi/é visto pela pessoa'.

Consideramos repetidamente o uso do hífen, especialmente para estes últimos casos, que indicaria a adjacência obrigatória e outros indícios que estas construções estão na fronteira entre sintaxe e morfologia. Concordamos, no entanto, que a introdução de uma terceira opção (junto / separado / hífen) introduziria mais complexidade do que estritamente necessária.

\section{A ordem alfabética}

Ao estabelecer uma ordem canônica para as letras em Awetí, para diversos fins (p.ex., para sua enumeração no ensino, para ordenar as entradas em um dicionário, etc.), em geral, seguimos a 'ordem alfabética' comum às línguas com a escrita latina. Há, porém, algumas questões a resolver. Com certa frequência, a ordem alfabética para línguas indígenas reserva uma posição para a representação de cada fonema, mesmo se esta representação for uma combinação de letras (dígrafo). Possivelmente, isto se deve ao fato de que as ortografias se baseiam muito diretamente na análise segmental da fonologia da língua e que elas querem ser fiéis a esta análise, facilitando, assim, a identificação das unidades fonológicas. Também é possível que haja influência de ortografias como a do espanhol, onde o $\langle\mathbf{I I}\rangle$, por exemplo, era uma 'letra' com uma posição à parte. ${ }^{28}$

Ora, para pessoas que estão adquirindo a escrita de uma língua (falantes nativos ou não), este arranjo sempre significa uma complicação adicional que pode leva-las a erros e frustrações. Outras ortografias não insistem em separar, na ordem alfabética, os dígrafos com valor fonêmico - por exemplo, em português não há uma posição à parte para o $\langle\mathbf{c h}\rangle$; este dígrafo (que representa o fonema $/ \mathbf{J} /$ ) é simplesmente tratado como a sequência de $\langle\mathbf{c}\rangle$ e $\langle\mathbf{h}\rangle$, e o mesmo vale para o $\langle\mathbf{l h}\rangle$ e o $\langle\mathbf{n h}\rangle$. O mesmo vale em alemão para $\langle\mathbf{i e}\rangle$, $\langle\mathbf{c h}\rangle$ e $\langle\mathbf{s c h}\rangle$, para $\langle\mathbf{s h}\rangle$ em inglês, $\langle\mathbf{o u}\rangle$ em francês, $\langle\mathbf{g h}\rangle$ e $\langle\mathbf{c h}\rangle$ em italiano, e assim por diante.

Ao determinar a ordem alfabética para o Awetí, optamos por essa segunda maneira de lidar com dígrafos - tratamos, então, o $\langle\mathbf{t s}\rangle$ como a sequência das letras $\langle\mathbf{t}\rangle$ e $\langle\mathbf{s}\rangle$ (sendo

${ }^{28}$ Observe que na reforma do espanhol de 2010 pela Real Academia Espanhola, esta posição própria dos dígrafos na ordem alfabética foi removida. Só o $\langle\tilde{\mathbf{n}}\rangle$ mantem sua posição especial, ao lado de $\langle\mathbf{n}\rangle$. 
que o $\langle\mathbf{s}\rangle$ só ocorre, em palavras nativas do Awetí, junto com o $\langle\mathbf{t}\rangle$; como acontece em Português em que o $\langle\mathbf{q}\rangle$ nunca ocorre sem que a letra contígua seja o $\langle\mathbf{u}\rangle)$.

Uma outra questão é o status da letra para a oclusiva glotal, $\left\langle{ }^{\prime}\right\rangle$. O primeiro impulso é que esta letra ocupe uma posição separada (usualmente no final do alfabeto), e de novo, isto pode ser uma fonte de constantes dificuldades para aprendizes da escrita da respectiva língua. Em Awetí, lembramos a distinção nada trivial dos três grupos de palavras discutida na seção 3.4. - é muito provável que um aprendiz da escrita Awetí tenha que procurar certas palavras em várias posições antes de achá-las num futuro dicionário se este usar uma ordem alfabética com uma posição separada para o 〈' $\rangle$.

Por isto, determinamos que a oclusiva glotal seja ignorada na determinação da ordem alfabética de palavras, ou seja, a palavra (202) 'ap 'cabelo principal' (da cabeça) se encontrará ao lado da palavra (203) ap 'cabelinho, pelo', na seção das palavras que começam com a vogal /a/. Se duas palavras se diferenciarem somente pela ocorrência ou não da glotal (como neste caso), a palavra com a glotal será colocada depois da palavra sem glotal (primeiro ap, depois 'ap, mas somente em seguida apaj e depois deste 'apo, por exemplo).

O mesmo vale para a ocorrência do til sobre uma vogal - esta é ignorada na ordem principal de palavras, mas no caso em que duas palavras se diferenciarem somente pelo til, a palavra com til será colocada depois da palavra sem ele.

A ordem alfabética do Awetí é, então, considerando que somente letras podem ocorrer em palavras nativas do Awetí:

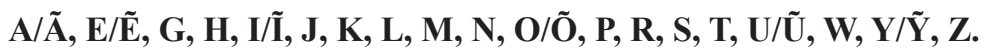

Além destas, há uma letra sem posição no alfabeto: $\left\langle{ }^{\prime}\right\rangle$ - se for necessário enumerar todas as letras em si, esta letra é colocada no final da lista.

Como exposto acima, os dois dígrafos do Awetí são tratados como sequências de letras:

$\langle\mathbf{n g}\rangle$ como a sequência de $\langle\mathbf{n}\rangle$ e $\langle\mathbf{g}\rangle$, e também

$\langle\mathbf{t s}\rangle$ como $\langle\mathbf{t}\rangle$ seguido por $\langle\mathbf{s}\rangle$.

A letras do Awetí que não ocorrem no início de palavras e que, portanto, não devem constituir capítulos no dicionário, são:

\section{$\mathbf{G}, \mathbf{R}, \mathbf{S}$.}

Pelo sistema fonológico, o $\langle\mathbf{z}\rangle$ deveria fazer parte deste grupo, mas acontece que em certas partículas (que obrigatoriamente seguem uma outra palavra, a saber, (204) zanu 'também', (205) zotsu 'somente', ver seção 6.4), o $\langle\mathbf{z}\rangle$ pode sim ocorrer no início. Também o som /y/ (e, portanto, o dígrafo 〈ng ), não ocorre no início de nenhuma palavra, a não ser na partícula $\boldsymbol{m} \boldsymbol{e}$ (final de sentença) depois de uma palavra que termina em /k/ ou /h/, quando esta partícula me apresenta a variante nge (cf. seção 4.5). No entanto, como explicamos 
acima, esta forma nge seria listada no capítulo "N" em algum lugar logo depois da palavra (206) nezuatu 'acreditar', mas antes de (207) nikatu 'procurar', já que dígrafos não são considerados como letras à parte.

Caso outras letras ocorram em palavras a serem incluídas em listas alfabéticas, por exemplo, palavras emprestadas do Português, estas vão ser colocadas na sua posição comum no alfabeto do latim ou de outras línguas. Aqui incluímos estas letras em itálico e sans-serif (em negrito letras que constituem capítulos num dicionário Awetí):

\section{$\mathbf{A} / \tilde{\mathbf{A}}, B, C, D, \mathbf{E} / \tilde{\mathbf{E}}, F, \mathrm{G}, \mathbf{H}, \mathbf{I} / \tilde{\mathbf{I}}, \mathbf{J}, \mathbf{K}, \mathbf{L}, \mathbf{M}, \mathbf{N}, \mathbf{O} / \tilde{\mathbf{O}}, \mathbf{P}, Q, \mathrm{R}, \mathbf{S}, \mathbf{T}, \mathbf{U} / \tilde{\mathbf{U}}, V, \mathbf{W}, X, \mathbf{Y} / \tilde{\mathbf{Y}}, \mathbf{Z}, '$}

\section{Conclusão}

Descrevemos aqui o sistema da escrita do Awetí e como este surgiu num processo colaborativo entre um linguista e a comunidade, em particular os dois professores Awetí, coautores deste trabalho, que está sendo constantemente refinado com base no progresso do estudo linguístico e na discussão dos problemas práticos e sugestões que surgiram em sala de aula e dos primeiros usuários da escrita do Awetí.

Como demonstramos aqui, uma ortografia não apenas estabelece a representação das vogais e das consoantes, mas também precisa abordar outras questões da escrita, como no Awetí é o caso de variação interna, ressilabificação, lenição, palatalização e outros processos (morfo)fonológicos. A representação escrita da oclusiva glotal foi objeto de atenção especial bem como as consequências ortográficas da harmonia nasal.

Ainda que o acento lexical não seja marcado em Awetí, a grande maioria dos afixos e partículas foi listada, considerando o acento e sua interação com morfemas adjacentes, ao mesmo tempo em que as palavras ortográficas foram determinadas. E, finalmente, foi estabelecida a ordem alfabética, onde dígrafos são tratados como sequências de letras, e a letra para a oclusiva glotal 〈'〉 e o til são ignorados, a fim de facilitar o aprendizado do Awetí.

Em geral, o sistema da escrita do Awetí agora encontra-se consolidado, visto que ele foi empregado (usualmente de maneira consistente, mais ou menos na forma atual) para transcrever um amplo corpus de textos orais coletados nos anos 1998 a 2010, e usado na alfabetização por uns 10 anos. Somente menores detalhes necessitam de mais estudo e possivelmente de um refinamento das regras, notadamente a questão das semivogais depois de consoantes (em particular no caso de ressilabificação), a questão da necessidade ou não da representação do acento lexical em pelo menos algumas palavras, e a representação da oclusiva glotal em início de certas palavras.

Acreditamos que as regras de escrita da língua Awetí acima estabelecidas e explicadas continuem se comprovando apropriadas no uso, isto é, que estão em sintonia com a estrutura da língua. Esperamos, assim, que sejam de utilidade para os seus usuários, contribuindo para fortalecer a língua Awetí. 


\section{DRUDE, W. AWETE e A. AWETI - A ortografia DA LÍnguA AWETí}

\section{Referências}

D’Angelis, Wilmar da Rocha (1994). Conquistar ou construir a escrita? A definição de uma ortografia no Ashaninka do Rio Amônia. Leitura, Teoria \& Prática 24: 3-19.

Drude, Sebastian (2002). Fala masculina e feminina em Awetí. In Ana Suelly A. C. Cabral; Aryon Dall'Igna Rodrigues (eds.). Linguas indígenas brasileiras: Fonologia, gramática e história. Atas do I Encontro Internacional do Grupo de Trabalho sobre Línguas Indigenas da ANPOLL, tomo 1, pp. 177-190. Belém: Editora UFPA . Versão em PDF disponível em: https://pure.mpg.de/rest/items/item_1466293/component/file_1466406/content (Acesso 19/06/2019).

Drude, Sebastian; Sabine Reiter \& Hans-Heinrich Lieb (2006). A documentation of the Aweti language and aspects of their culture [Multimedia Language Archive]. Com contribuição de Waranaku Aweti, Awajatu Awetí, Yakumin Aweti, Tawyjat Aweti, Parawajru Aweti, Xiaoqin Su, Eva-Maria Roessler, e outros. Nimegue, Países Baixos: Max-Planck-Institute for Psycholinguistics. DoBEs-Programme / VolkswagenStiftung. http://hdl.handle.net/hdl:1839/00-0000-0000-0001-305C-A

Drude, Sebastian. (2009). Nasal harmony in Awetí - A declarative account. ReVEL - Revista Virtual de Estudos Da Linguagem 3. Disponível em: http://www.revel.inf.br/files/artigos/revel special_3 nasal harmony in aweti.pdf (Acesso 18/06/2019).

Drude, Sebastian (2011). Word accent and its manifestation in Awetí. In: Francesc Queixalós; Leo Wetzels (eds.). Amerindia 35: 189-218. (Edição especial 'Estrutura das línguas Amazônicas'). Disponível em: http://www.vjf.cnrs.fr/sedyl/amerindia/articles/pdf/A 35 02.pdf (Acesso 18/06/2019).

Drude, Sebastian (em preparação). A fonologia da língua Awetí.

Eisenberg, Peter (1983). Orthographie und Schriftsystem. In Klaus B. Günther; Hartmut Günther (eds.). Schrift, Schreiben, Schriftlichkeit, pp. 41-68. Tübingen: Niemeyer (Germanistische Linguistik 49).

Emmerich, Charlotte; Monserrat, Ruth M. F. (1972). Sobre a fonologia da língua Aweti (Tupi). Boletim do Museu Nacional N.S. Antropologia 25: 1-18.

Figueiredo, Marina Vanzolini (2009). Escrever, ouvir: perspectivas sobre o saber entre os Aweti do Alto Xingu. Ide 32/48: 147-162. São Paulo. Disponível em: http://pepsic.bvsalud.org/pdf/ide/v32n48/v32n48a17.pdf (Acesso 19/06/2019).

Franchetto, Bruna (2008). A guerra dos alfabetos: Os povos indígenas na fronteira entre o oral e o escrito. MANA: Estudos de Antropologia Social 14(1): 31-59. Rio de Janeiro: PPGAS/ Museu Nacional.

Disponível em: http://www.scielo.br/pdf/mana/v14n1/a02v14n1.pdf (Acesso 19/06/2019).

Fuhrhop, Nana (2005). Orthografie. (Kurze Einführungen in die germanistische Linguistik 1). Heidelberg: Winter.

Meira, Sérgio (2004). O linguista e a ortografia indígena: O caso da língua Bakairi. Revista de Estudos e Pesquisas 1(2): 73-99. Disponível em: http://www.funai.gov.br/arquivos/conteudo/cogedi/pdf/Revista-Estudos-e-Pesquisas/revista_estudos pesquisas v1 n2/Artigo-3-Sergio-Meira.pdf (Acesso 19/06/2019). 
Monserrat, Ruth M. F. (1976). Notas sobre a morfofonêmica Aweti. Rio de Janeiro. (Manuscrito para apresentação oral.)

Monserrat, Ruth M. F. (1992). Proposta de um alfabeto para a lingua Aweti (Manuscrito.)

Postigo, Adriana Viana (2014). Língua Wauja (Arawák): Uma descrição fonológica e morfossintática (Tese de doutorado). Araraquara: Universidade Estadual Paulista "Júlio de Mesquita Filho".

Disponível em: http://www.etnolinguistica.org/tese:postigo-2014

Rodrigues, Aryon Dall'Igna (1986). Linguas Brasileiras. Para o Conhecimento das Linguas Indigenas (Missão Aberta 11). São Paulo: Ed. Loyola.

Rodrigues, Aryon Dall'Igna (1999). Tupí. In Robert M. W. Dixon; Alexandra Y. Aikhenvald (eds.). The Amazonian languages, pp. 107-124. Cambridge: Cambridge University Press.

Rodrigues, Aryon Dall'Igna; Cabral, Ana Suelly Arruda Câmara (2012). Tupían. In Lyle R. Campbell; Verónica María Grondona (eds.). The indigenous languages of South America: A comprehensive Guide, pp. 495-547. Berlin, Boston: De Gruyter Mouton.

Troncarelli, Maria Christina; Drude, Sebastian; Würker, Estella (eds.) (2002). Awytyza Ti’ingku. Livro para alfabetização na língua Awetí. São Paulo: Instituto Socioambiental.

Recebido: 19/6/2019

Versão revista e corrigida: 22/8/2019

Aceito: 16/9/2019.

LIAMES, Campinas, SP, v. 19, 1-23, e019014, 2019 